\title{
The U.S. Department of Energy
}

SUNY Beamline Facilities at the

National Synchrotron Light Source

\section{FINAL REPORT}

November 1, 2001 - April 30, 2003 
Submitted to:

DOE award number:

Awardee:

Research Site:

Title of Project:

Principal Investigator:
The U. S. Department of Energy

Washington, D.C. 20585

DE-FG02-86ER45231

The Research Foundation of the State

University of New York at Buffalo

UB Commons, Suite 211

Buffalo, New York 14260

Telephone: (716) 645-2977

for and in conjunction with

The State University of New York at Buffalo

Buffalo, New York 14260

(Congressional District \#31)

The State University of New York at Buffalo and Brookhaven National Laboratory

SUNY Beamline Facilities at the National Synchrotron Light Source

Philip Coppens,

Distinguished Professor of Chemistry

Telephone: (716) 645-6800 ext. 2217 


\section{Executive Summary}

\section{Scope of the project}

The DOE sponsored SUNY synchrotron project has involved close cooperation among faculty at several SUNY campuses. A large number of students and postdoctoral associates have participated in its operation which was centered at the X3 beamline of the National Synchrotron Light Source at Brookhaven National Laboratory.

Four stations with capabilities for Small Angle Scattering, Single Crystal and Powder and Surface diffraction and EXAFS were designed and operated with capability to perform experiments at very low as well as elevated temperatures and under high vacuum. A large amount of cuttingedge science was performed at the facility, which in addition provided excellent training for students and postdoctoral scientists in the field.

\section{Summary of scientific accomplishments}

\section{Time-Resolved Diffraction of Transient Molecular Species}

Excited high-energy states of molecules are extremely reactive and knowledge of their structure can significantly contribute to the understanding of chemical processes. Chemistry is essentially a science of molecular change as chemical processes are dynamic and reaction pathways and their transition states play a crucial role in determining the products of chemical reactions. Crystallography has traditionally been performed on ground-state structures, but this limitation is now being eliminated. The first time-resolved single-crystal experiments of $\mu$ sec lifetime transient species at atomic resolution were performed by laser-pump X-ray probe experiments on a dinuclear platinum complex, showing a large molecular change with a significant Pt-Pt bond length contraction in its laser-excited state. The results agree qualitatively with those from theoretical calculations but often differ quantitatively, as the theoretical calculations tend to vary with computational method. The importance of appropriate relativistic corrections in computations on molecules containing heavier metal atoms is evident. The technical information gained in these experiments is now being applied at the Advanced Photon Source at Argonne National Laboratory. 


\section{Charge Density Studies of the Electronic Structure of Molecules and Solids}

As a result of technical advances including the advent of synchrotron radiation, area detectors and low-cost high-speed computing, X-ray analysis is being increasingly used to map the electron distribution (ED) in molecules and solids. The X3 beamline was developed into a prime station for the collection of the accurate diffraction data needed for this purpose, and in the course of its existence attracted many researchers from abroad who came to participate in the program. Data were collected on a variety of solids, including biologically important amino acids and oligopeptides and a series of transition metal complexes of iron, chromium copper, zirconium and other elements. The peptide data were used to calculate intermolecular electrostatic interactions for an ongoing program to study the strength of receptor-drug and enzyme-substrate interactions and explain observed differences in association energies. The metal complex data were used to analyze the nature of metal-ligand interactions and compare the results with theoretical predictions obtained in a parallel computational effort. Increased polarization of molecules by the crystalline environment is evident from the results.

\section{Microcrystallography of Porous Materials and High Pressure Phases}

Structures of complex newly synthesized porous material were determined from crystals as small as $20 \mu \mathrm{m}$, as part of a program of exploratory syntheses to search for crystalline solids with enhanced ion exchange capacity and selectivity. Data obtained suggest the pathway of ion exchange in these high capacity materials to be structure dependent, as exchange proceeds more accessible and more weakly bonded ions are exchanged. High-pressure phases of importance to understanding the Earth's interior and several new materials related to the bone mineral apatite were examined

\section{$\underline{\text { Powder Diffraction }}$}

Because of its brightness and low divergence, synchrotron radiation is eminently suited for structure determination of quite complex solids by powder diffraction. While many structures can be solved with powder data from laboratory sources, the combination of resolution, intensity, and tunability make synchrotron radiation invaluable for the harder problems as well as for relatively simple problems involving air-sensitive samples. The X3 beamline has been one of the few resources within the entire spectrum of DOE facilities dedicated to the determination of the atomic 
structures of new microcrystalline materials, and dedicated to building a community of investigators conversant with these techniques. Besides the experimental data, the research has extended to the continuing development of software for structure solution by simulated annealing. Accomplishments of the project include the development and application of sophisticated methods for determination of organic structure from powder diffraction data. Among the structures determined from powder data is that of synthetic $\beta$-hematine or hemazoin, commonly known as malaria pigment and the asthma drug, R-salbutamol sulfate, the active ingredient in ventoline.

Commercial thin film optical coatings on float glass were characterized using specular and diffuse X-ray reflectivity, to determine thickness, density, and interface roughness of each coating, and diffuse scattering to determine surface and subsurface interface roughness. Silver metal formation in imaging, equipment and methods was studied to determine the kinetics and activation energies of the reactions involved.

\section{$\underline{\text { Wide and Small Angle Scattering of Polymers }}$}

The extensive studies performed involved in situ experiments on the crystallization and structure formation of industrially important polymers such as the polyester poly(ethylene terephthalate), isotactic and syndiotactic polypropylene and block copolymers. Quantitative information was obtained on the isotropic and anisotropic fractions formed and the effect of additives, temperature change and stress on the crystallization rate and the nature of the products.

\section{$\underline{\text { Nanoscale Structures }}$}

A major effort was made in the development of X-ray characterization techniques, and applications of these techniques in the study of various semiconductor systems of fundamental and practical interest, including investigation of nanometer-scale structures in thin films and quantum dots of compound semiconductors, essential for the development of innovative next generation photonic, electronic, and magnetic devices and studies of atomic and nanoscale structure in various types of photovoltaic (PV) materials to correlate various PV characteristics with the microscopic structures determined by the X-ray measurements. 


\section{X3 Beamline Publications and Presentations by SUNY PRT Members (2000- present)}

\section{Articles}

\section{0}

Y.A. Abramov, A. Volkov \& P. Coppens, "Anisotropic atom-atom potentials from X-ray charge densities: application to intermolecular interactions and lattice energies in some biological and nonlinear optical materials", J. Mol. Struct. (THEOCHEM) 2000, 529, 27-35.

Y.A. Abramov, A. Volkov, G. Wu \& P. Coppens, "The Experimental Charge Density Approach (ECDA) in the evaluation of intermolecular interactions. Application of a new module of the XD programming package to several solids including a pentapeptide", Acta Crystallogr. A 2000, 56, 585-591.

R.E. Dinnebier, "Long Standing Problems in Organometallic Chemsitry Solved by Powder Diffraction", Proc. 6th Europ. Powder Diffract. Conf., Budapest, August 22-25, 1998, Materials Science Forum, in press.

R.E. Dinnebier, M. Schweiger, B. Bildstein, K. Shankland, W.I.F. David, A. Jobst \& S. van Smaalen, "The disordered structure of tetraferrocenyl-[3]-cumulene $(\mathrm{Fc})_{2} \mathrm{C}=\mathrm{C}=\mathrm{C}=\mathrm{C}(\mathrm{Fc})_{2}$ by simulated annealing using synchrotron powder diffraction data", J. Appl. Crystallogr. 2000, 33, 1199-1207.

R.E. Dinnebier, P. Sieger, H. Nar, K. Shankland \& W.I.F. David, "Structural characterization of three crystalline modifications of telmisartan by single crystal and high-resolution X-ray powder diffraction", J. Pharm. Sci. 2000, 89, 1465-1479.

Y. Lee, J.B. Parise, A. Tripathi, S.J. Kim \& T. Vogt, "Synthesis and crystal structures of gallium and germanium variants of cancrinite", Micropor. Mesopor. Mater. 2000, 39, 445-455.

T. Liu, Y. Xie \& B. Chu, "Use of block copolymer micelles on formation of $\mathrm{MoO}_{3}$ nanospheres," Langmuir 2000, 16, 9015-9022.

T. Liu, Y. Xie, L.-Z. Liu \& B. Chu, "Salt-induced microphase separation and crystallization in saltpolymer complex systems", Langmuir, Note, 2000, 16, 7533-7537. 
P.F. Miceli, S.A. Sahiner, C. Botez, W.C. Elliott \& P.W. Stephens, "Two-dimensional small angle scattering from submonolayer islands", Adv. X-ray Anal. 2000, 43, 200-207.

S. Misture, "The effect of water content on neodymium doped fluorozirconate and fluoroaluminate glasses", Proc. Int. Soc. Optic. Eng., SPIE, Paper 4102-26, Vol. 4102, in press.

S. van Smaalen, R.E. Dinnebier, R. Milletich, M. Kunz, I. Holleman, G. von Helden \& G. Meijer, "Compressibility of CO intercalated $\mathrm{C}_{60}$ crystals", Chem. Phys. Lett., in press.

Y.L. Soo, S. Huang, S. Kim, G. Kioseoglou, Y.H Kao, A.D. Compaan, D. Grecu \& D. Albin, "Effects of heat treatment on diffusion of $\mathrm{Cu}$ atoms into CdTe single crystals", Appl. Phys. Lett. 2000, 76, 3729-3731.

S. Zhou, F.Yeh, C. Burger, H. Hu, T. Liu \& B. Chu, "SAXS study on complexes formed by anionic poly(sodium methacrylate-co-N-isopropylacrylamide) gels with cationic surfactants", Polymers Adv. Tech. 2000, 11, 235-241.

\section{1}

C.E. Botez, W.C. Elliott, P.F. Miceli \& P.W. Stephens, "Thermal expansion of the Ag(111) surface measured by X-ray scattering”, Phys. Rev. B 2001, 63, 113404/1-113404/4.

C.E. Botez, P.F. Miceli \& P.W. Stephens, “Temperature dependence of the surface roughening during the homoepitaxial growth on $\mathrm{Cu}(100)$ ", Physical Review B 2001, 64, 125427/1-125427/6.

M.L. Bushey, A. Hwang, P.W. Stephens \& C. Nuckolls, "Enforced stacking in crowded arenes", J. Amer. Chem. Soc. 2001, 123, 8157-8158. "Editor's Choice” in Science 2001, 293, 1224. "Science Concentrate" in Chemical and Engineering News 2001, 79, 36.

Y.-H. Cheng, Y.-L. Soo, S. Huang, G. Kioseoglou, S.-S. Kim, Y.-H. Kao, B.-H. Tseng, H.-H. Hung, T.-E. Dann \& H.-L. Hwang, "Comments on surface studies and surface alteration of $\mathrm{CuInSe}_{2}$ polycrystalline thin films", Japanese J. Applied Physics, 2000, 39, Suppl. 39-1, pp 379-381.

A. Dertinger, R.E. Dinnebier, A. Kreyssig, P.W. Stephens, S. Pagola, M. Loewenhaupt, S. van Smaalen \& H.G. Braun, "Microscopic changes in $\mathrm{HoNi}_{2} \mathrm{~B}_{2} \mathrm{C}$ due to thermal treatment, and its effect on superconductivity", Phys. Rev. B 2001, 63, 184518/1-184518/7.

R.E. Dinnebier, L. Ding, K. Mab, M.A. Neumann, N. Tanpipat, F.J.J. Leusenc, P.W. Stephens \& M. Wagner, "Crystal structure of a rigid ferrocene-based macrocycle from high-resolution X-ray powder diffraction", Organometallics 2001, 20, 5642-5647

B.X. Fu, L. Yang, R.H. Somani, S.X. Zong, B.S. Hsiao, S. Phillips, R. Blanski \& P. Ruth, 
"Crystallization studies of isotactic polypropylene containing nanostructured polyhedral oligomeric silsesquioxanes (POSS) molecules under quiescent and shear conditions”, J. Polym. Sci. Polym. Phys. 2001, 39, 2727-2739.

B.X. Fu, W. Zhang, B.S. Hsiao, M. Rafailovich, J. Sokolov, G. Johansson, B.B. Sauer, S. Phillips \& R. Blanski, "Synthesis and characterization of segmented polyurethane containing polyhedral oligomeric silsesquioxane (POSS) nanostructured molecules", High Performance Polymer 2001, $12,565-571$.

M.I. Gómez, G. Lucotti, J.A. de Morán, P.J. Aymonino, S. Pagola, P.W. Stephens \& R.E. Carbonio, "Ab-initio structure solution of $\mathrm{BaFeO}_{2.8-\delta}$, a new polytype in the system $\mathrm{BaFeO}_{\mathrm{y}}(2.5 \leq y \leq 3.0)$ prepared from the oxidative thermal decomposition of $\mathrm{BaFe}\left[(\mathrm{CN})_{5} \mathrm{NO}\right] \cdot 3 \mathrm{H}_{2} \mathrm{O}$ ", J. Solid State Chem. 2001, 160, 17-24.

S. Huang, Y.L. Soo, Y.H. Kao \& A.D. Compaan, "Effects of thermal annealing on the interface morphology of CdTe/CdS heterojunctions", J. Vac. Sci. Technol. A 2001, 19, 2181-2185.

A. Huq, P.W. Stephens, G.M. Bendele \& R.M. Ibberson, "Polymeric fullerene chains in $\mathrm{RbC}_{60}$ and $\mathrm{KC}_{60}$ ", Chem. Phys. Lett. 2001, 347, 13-22.

Y.H. Kao, S. Kim, Y.L. Soo \& G. Kioseoglou, "Intermixing of atoms across heterointerfaces in thin film photovoltaic materials: nondestructive X-ray characterization using synchrotron radiation”, Photovoltaics for the 21st Century II, Proceedings of the International Symposium, The Electrochemical Society Proceedings 2001-10, 349 (2001).

S. Kim, Y.L. Soo, G. Kioseoglou, Y.H. Kao \& X. Wu, "Nondestructive characterization of atomic density profile in $\mathrm{CdS} / \mathrm{Zn}_{2} \mathrm{SnO}_{4}$ junctions by X-ray fluorescence", Proc. of NCPV Program Review Meeting, Lakewood, Co, 239 (2001).

H. Kisch, B. Eisen, R. E. Dinnebier, K. Shankland, W.I.F. David \& F. Knoch, "Chiral metal dithiolene - viologen ion pairs - synthesis and electrical conductivity", Chem. Eur. J. 2001, 7, 738-748.

P. Macchi, A.J. Schultz, F.K. Larsen \& B.B. Iversen, "Experimental and theoretical electron density study of the peroxo function in oxoperoxo(pyridine-2,6-dicarboxylato) (hexamethylphosphoramide)molybdenum(VI): implications for olefin epoxidation by peroxo transition metal complexes", J. Phys. Chem. A 2001, 105, 9231-9242. 
R.J. McQueeney, J.L. Sarrao, P.G. Pagliuso, P.W. Stephens \& R. Osborn, "Mixed lattice and electronic states in high-temperature superconductors", Phys. Rev. Letters 2001, 87, 077001/1077001/4.

S.T. Misture, "Renaissance of X-ray characterization for coatings and surfaces of glass", The Glass Researcher, Millennium Issue 2001, 10-11, 16-17, 51.

M. Nyman, A. Tripathi, J.B. Parise, R.S. Maxwell, W.T.A. Harrison \& T.M. Nenoff, “A new family of octahedral molecular sieves: sodium Ti/ZrIV niobates", J. Am. Chem. Soc. 2001, 123, 15291530.

J. Overgaard, B. Schiøtt, F.K. Larsen \& B.B. Iversen, "The charge density distribution in a model compound of the catalytic triad in serine proteases”, Chem. Eur. J. 2001, 7, 3756-3767.

S. Ran, X. Zong, D. Fang, B.S. Hsiao, B. Chu \& R.A. Phillips, "Structural and morphological studies of isotactic polypropylene fibers during heat/draw deformation by in-situ synchrotron SAXS/WAXD”, Macromolecules 2001, 34, 2569-2578.

S. Ran, X. Zong, D. Fang, B.S. Hsiao, B. Chu, PM. Cunniff \& R.A. Phillips, "Study of the mesophase in polymeric fibers during deformation by synchrotron SAXS/WAXD”, J. Mater. Sci. 2001, 36, 3071-3077.

S. Ran, Z. Wang, C. Burger, B.S. Hsiao \& B. Chu, "Strain-induced crystallization of PET film from the glassy state: in-situ X-ray diffraction studies”, ACS Meeting, Chicago, Aug. 2001, Vol. 85, 565-566.

Y.L. Soo, S. Huang, S. Kim, G. Kioseoglou, Y.H. Kao, A.D. Compaan, D. Grecu \& D. Albin, "Effects of heat treatment on diffusion of $\mathrm{Cu}$ atoms into CdTe single crystals", Appl. Phys. Lett. 2000, 76, 3729-3731.

Y.L. Soo, S.W. Huang, Y.H. Kao, Y.W. Yang, L.J. Lai, V. Chhabra, B. Kulkarni, J.V.D. Veliadis \& R.N. Bhargava, "Size variation of Tb-Doped $\mathrm{Gd}_{2} \mathrm{O}_{3}$ nanoparticles studied by X-ray excited luminescence and diffraction", Modern Physics Letter B 2001, 15, 205-211.

Y.L. Soo, G. Kioseoglou, S. Kim, Y.H. Kao, S. Kuwabara, S. Owa, T. Kondo \& H. Munekata, "Local structure and chemical valency of Mn impurities in wide-band gap III-V magnetic alloy semiconductors $\mathrm{Ga}_{1-\mathrm{x}} \mathrm{Mn}_{\mathrm{x}} \mathrm{N} "$, Appl. Phys. Lett. 2001, 79, 3926-3928.

Y.L. Soo, S. Kim, G. Kioseoglou \& Y.H. Kao, "Probing the interface morphology and atomic distribution in photovoltaic materials using synchrotron radiation", Proc. of NCPV Program Review Meeting, Lakewood, Co, P235-236 (2001). 
Y.L. Soo, S. Huang, Y.H. Kao, S.K. Deb, K. Ramanathan \& T. Takizawa, "Probing the interface and microstructures in $\mathrm{CdS} / \mathrm{CuInSe}{ }_{2}$ and $\mathrm{InGaAsN} / \mathrm{GaAs}$ heterojunctions by synchrotron radiation", Japanese J. Applied Physics, 2000, 39, Suppl. 39-1, pp 29-34.

C. Tedesco, R.E. Dinnebier, F. Olbrich \& S. van Smaalen, "The disordered crystal structure of pentamethylcyclopentadienylsodium $\mathrm{NaCp}^{*}$ as seen by high resolution X-ray powder diffraction", Acta Crystallogr. B 2001, 57, 673-679.

A. Tripathi, J.B. Parise, S.J. Kim, Y. Lee \& Y.S. Uh, " $\mathrm{K}_{5.76} \mathrm{Ga}_{5.76} \mathrm{Si}_{10.24} \mathrm{O}_{32} \cdot 3.4 \mathrm{H}_{2} \mathrm{O}$, a gallosilicate with the zeolite gismondine topology", Acta Crystallogr. C 2001, 57, 344-346.

A. Volkov, Yu.A. Abramov and P. Coppens, "Density optimized radial exponents for X-ray charge density refinement from ab initio crystal calculations”, Acta Crystallogr. A 2001, 47, 272-282.

Z.-G. Wang, B.S. Hsiao \& C.C. Han, "Evolution of morphology and structure during crystallization and melting in syndiotactic polypropylene”, Chinese J. App. Chem. (Yingyong Huaxue) 2001, 18, 280-288.

\section{2}

T. Blanton, M. Lelental, S. Zdzieszynski \& S.T. Misture, "In-situ high temperature study of silver behenate reduction to silver metal using synchrotron radiation", Adv. X-Ray Anal. 2002, 45, 371376.

R.E. Dinnebier, S. Jelonek, J. Sieler \& P.W. Stephens, “The solid state structures of K salicylate and $\mathrm{Rb}$ salicylate by high resolution X-ray powder diffraction", Z. Anorg. Allg. Chemie 2002, 628, 363-368.

R. Dinnebier, H.W. Lerner, L. Ding, K. Shankland, W.I.F. David, P.W. Stephens \& M. Wagner, "One-dimensional spin chains from $\mathrm{Cu}^{\mathrm{II}}$ ions and 2,5-bis(pyrazol-1-yl)-1,4-dihydroxybenzene", Z. Anorg. Allg. Chem. 2002, 628, 310-314.

A. Hönnerscheid, R.E. Dinnebier \& M. Jansen, "Reversible dimerization of $\mathrm{C}_{60}$ molecules in the crystal structure of bis(arene)chromium fulleride $\mathrm{Cr}\left(\mathrm{C}_{7} \mathrm{H}_{8}\right)_{2} \mathrm{C}_{60}$ ", Acta Crystallogr. B 2002, 58, 482-488.

C.D. Kim, S. Pillet, G. Wu, W.K. Fullagar \& P. Coppens, "Excited state structure by time-resolved X-ray diffraction", Acta Crystallogr. A 2002, 58, 133-137. 
G. Kioseoglou, S. Kim, Y.L. Soo, X. Chen, H. Luo, Y.H. Kao, Y. Sasaki, X. Liu \& J.K. Furdyna, "Investigation of nanoscale structure in digital-layers of $\mathrm{Mn} / \mathrm{GaAs}$ and $\mathrm{MnGa} / \mathrm{GaAs}$ ", Appl. Phys. Lett. 2002, 80, 1150-1152.

A. Piotrowski, V. Kahlenberg, R.X. Fischer, Y. Lee \& J.B. Parise, “The crystal structure of cesanite and its synthetic analogue - a comparison”, Am. Mineralalogist 2002, 87, 715-720.

P.W. Stephens, D.E. Cox \& A.N. Fitch, "Synchrotron Radiation Powder Diffraction”, to appear as a chapter in Structure Determination by Powder Diffraction, W.I.F. David, K. Shankland, L.B. McCusker and C. Baerlocher (Eds); Oxford University Press, 2002.

G. Wu, B. L. Rodrigues \& P. Coppens, "The correction of reflection intensities for incomplete absorption of high energy X-rays in the CCD phosphor”, J. Appl. Crystallogr. 2002, 35, 356-359.

\section{3}

T. Asthalter, H. Franz, U. van Burck, K. Messel, E. Schreier \& R. Dinnebier, "Structure and dynamics of octamethyl-ethynyl-ferrocene: an organometallic rotator phase", J. Phys. Chem. Solids 2003, 64, 677-684.

C.E. Botez, W.C. Elliott, K. Li, E.D. Lu, P.F. Miceli, E.H. Conrad \& P.W. Stephens, "Specular reflectivity from pyramidal surface morphologies", Physica B 2003, 336, 130-135.

R.E. Dinnebier, S. Vensky, M. Panthoefer \& M. Jansen, "Crystal and molecular structures of alkali oxalates: first proof of a staggered oxalate anion in the solid state", Inorg. Chem. 2003, 42, 14991507.

A. Huq \& P.W. Stephens, "Subtleties in crystal structure solution from powder diffraction data using simulated annealing: Ranitidine hydrochloride”, J. Pharm. Sci. 2003, 92, 244-249.

I. Novozhilova, A.V. Volkov \& P. Coppens, "Theoretical analysis of the triplet excited state of the $\left[\mathrm{Pt}_{2}\left(\mathrm{H}_{2} \mathrm{P}_{2} \mathrm{O}_{5}\right)_{4}\right]^{4-}$ ion and comparison with time-resolved X-ray and spectroscopic results", J. Am. Chem. Soc. 2003, 125, 1079-1087.

S. Pillet, G. Wu, V. Kulsomphob, B.G. Harvey, R.D. Ernst \& P. Coppens, "Investigation of Zr-C, $\mathrm{Zr}-\mathrm{N}$ and potential agostic interactions in an organozirconium complex by experimental electron density analysis", J. Am. Chem. Soc. 2003, 125, 1937-1949. 
L.X. Chen, G.B. Shaw, I. Novozhilova, T. Liu, G. Jennings, K. Attenkofer, G.J. Meyer \& P. Coppens, "The MLCT state structure and dynamics of a copper(I) diimine complex characterized by pump-probe X-ray and laser spectroscopies and DFT calculations", J. Am. Chem. Soc. 2003, $125,7022-7034$.

P. Coppens, "What can time-resolved diffraction tell us about transient species?: excited-state structure determination at atomic resolution”, Chem. Commun. (Focus article) 2003, 1317-1320.

\section{Ph.D. Theses}

B.X. Fu, "Polymer nanocomposites based on polyhedral oligomeric silsesquioxanes', State University of New York at Stony Brook, USA (2002).

C.D. Kim, "The use of $\left[\mathrm{Pt}_{2}\left(\mathrm{P}_{2} \mathrm{O}_{5} \mathrm{H}_{2}\right)_{4}\right]^{4-}$ and selected model rhodium(III) compounds in the development of single crystal monochromatic excited-state crystallography", State University of New York at Buffalo, USA (2002).

B.B. Iversen, "Charge density studies of chemical bonding", University of Aarhus, Denmark (2003).

J. Overgaard, "Utilizing the versatility of X-ray diffraction in chemistry. Charge density analyses and structural correlations", University of Aarhus, Denmark (2001).

$\mathrm{X}$. Zong, "Processing-structure/morphology-property relationships in nano-scale fibers and their biomedical applications", State University of New York at Stony Brook, USA (2002).

\section{Masters Theses}

K.E. Christensen, "X-ray diffraction studies of disorder in structures of transitionmetalcomplexes with carboxylic acid ligands", University of Aarhus, Denmark (2001).

R.D. Poulsen, "Experimental X-ray charge densities in crystals", University of Aarhus, Denmark (2003). 


\section{Lectures / Papers Presented at Conferences}

\section{Benjamin Chu}

Third Annual University-Industry Workshop on Structure in Nanocomposite Materials and Neutron Applications, Taejon, Korea, 2000:

"Particle synthesis for biomedical and industrial applications," B. Chu (invited talk)

APS March Meeting, Minneapolis, MN, 2000:

“Crystallization of modified hollow $\mathrm{MoO}_{3}$ nanospheres," T. Liu, Y. Xie and B. Chu (talk)

ACS March Meeting, Symposium on Polymer Gels, 2000:

"Synchrotron X-Ray studies on nanostructures of polyelectrolyte gel/surfactant complexes," B. Chu and $\underline{\text { S. Zhou (talk) }}$

Colloquium, Chemistry Department and Institute of Materials Science, University of Connecticut: "Structural evolution of high-strength fiber processing", B. Chu (invited talk)

Advanced Polymeric Materials and Technology (APMT-2003), Gyeongju, Korea (organized by Korea Advanced Institute of Science and Technology (KAIST) and Tokyo Institute of Technology (TIT):

"Structural evolution of high-strength fiber processing”, B. Chu (invited talk)

\section{Philip Coppens}

International Workshop on High-precision, High-resolution Analysis Methods of Electronic States of Solids, Tsukuba, Japan, March 7-9, 2000:

"The use of high-resolution X-ray diffraction experiments in the evaluation of intermolecular interactions and lattice energies: application to some biological and non-linera optical materials and comparison with theory", Y. Abramov, A. Volkov, G. Wu and P. Coppens (invited talk) 
$19^{\text {th }}$ European Crystallographic Meeting, Nancy, France, Aug. 25-31, 2000:

"The study of light-induced transient species by crystallographic methods", P. Coppens (invited talk)

"Application of the theory of atoms in molecules in the critical analysis of the experimental charge density model", A. Volkov, Yu. Abtamov and P. Coppens (invited talk)

"Intermolecular interaction energies from the X-ray charge density", Yu.A. Abramov, A. Volkov and P. Coppens (poster)

Sagamore XIII Conference on Charge, Spin and Momentum Densities, Stare Jablonki, Poland, Sept. 3-9, 2000:

"Review of current trends in the experimental charge density study", Y.A. Abramov (invited talk)

Pacifichem 2000, Honolulu, Hawaii, Dec. 14-19, 2000:

“Time-resolved diffraction studies of transient metastable electronically excited states", P. Coppens (invited talk)

The Institute of Chemistry in Sao Carlos at the University of Sao Paulo, Brazil, Sept. 30 - Oct. 7, 2000 (invited talks by P. Coppens):

1. An overview of charge density studies

2. Topological Analysis of experimental charge densities

3. Electrostatic moments and lattice energies from experimental charge densities

4. Charge density studies of transition metal complexes

Workshop on High-Energy X-ray Scattering at the APS, Argonne National Laboratory, March 8-9, 2001:

"Hard X-rays: the radiation of choice for high-accuracy diffraction studies of solids", P. Coppens (invited talk)

German Synchrotron Facility, Hasylab, Hamburg, Germany, June 22, 2001:

"Time-resolved single-crystal studies at the SUNY X3 beamline at NSLS", P. Coppens (invited talk) 
British Crystallographic Association Spring Meeting, University of Reading, UK, April 7-10, 2001:

"Combining crystallography and photochemistry in the study of light-induced metastable states and transient species", P. Coppens (invited talk)

Department of Chemistry and Biochemistry, the University of Oklahoma, Norman, OK, Feb. 22, 2001:

"Crystallography and photochemistry: can they be combined to study chemical and biological processes at the atomic level?", P. Coppens (invited talk)

Indian Institute of Science, Bangalore, India, Jan. 10, 2001:

"Photocrystallographic studies of light-induced metastable states and transient species", P. Coppens (invited talk)

School of Chemistry, University of Hyderabad, India, Jan. 9, 2001; and National Chemistry Laboratory, Pune, India, Jan. 15, 2001:

"Photo-induced changes in molecular crystals: metastable states of transition metal nitrosyl complexes and the study of transient species by time-resolved diffraction", P. Coppens (invited talk)

University of Delaware, April 17, 2002:

"Combining photochemistry and crystallography: photocrystallographic studies of light-induced metastable states of transition metal complexes and short-lived transient species", P. Coppens (invited talk)

Texas A\&M, May 1, 2002:

"Studies of laser-generated transient states by X-ray diffraction”, P. Coppens (invited talk)

ACA Annual Meeting, San Antonio, TX, May 25-30, 2002:

"Theoretical Excited State Calculations vs. Time-resolved Crystallography: the $\left[\mathrm{Pt}_{2}\left(\mathrm{H}_{2} \mathrm{P}_{2} \mathrm{O}_{5}\right)_{4}\right]^{4-}$ ion", P. Coppens 
Faraday Discussion 122 on "Time Resolved Chemistry: From Structure to Function", Manchester, UK, June 24-26, 2002:

“Time-resolved chemistry”, P. Coppens (introductory lecture)

CrystEngComm Discussion1: Innovation in Crystal Engineering, June 29-July 1, 2002:

"Crystal engineering and time-resolved diffraction", P. Coppens (invited talk)

XIX Congress and General Assembly of the International Union of Crystallography, Geneva, Switzerland, August 6-15, 2002:

"Stroboscopic time-resolved diffraction at atomic resolution", P. Coppens

Finn Krebs Larsen (University of Aarhus, Denmark):

Higher European Research Course for Users of Large Experimental Facilities, European Synchrotron Research Facility, March 20, 2003:

"Single crystal diffraction. Electron density mapping as part of the European HERCULES PhD course", F.K. Larsen

\section{Benjamin S. Hsiao}

APS Meeting, Minneapolis, MN, March 2000:

"Crystallization of polymers in confined environments: structural development of semi-crystalline polymer-layered silicate nanocomposites", R.A. Vaia, D. Lincoln, Z.-G. Wang, B.S. Hsiao and R. Krishnamoorti, (talk)

"Time-resolved steady shear study of end-thetered nylon6-clay nanocomposites followed by nonisothermal crystallization", F.J. Medellin-Rodriguez, B. Hsiao, B. Chu, R. Vaia and S Phillips (talk)

ACS Meeting, San Fracisco, CA, March 2000: 
"Synthesis and characterization of novel segmented poly(urethanes) containing polyhedral oligimeric silsesquioxanes (poss) nanostructured molecules", B.X. Fu, W. Zhang, B.S. Hsiao, G. Johansson, B.B. Sauer, S. Phillips, R. Blanski, M. Rafailovich and J. Sokolov (poster)

APS Meeting, March, Seattle, WA, 2001:

"In-situ X-ray studies of molecular orientation enhancement in polyhedral oligomeric silsesquioxanes(POSS)/iPP nanocomposites", L Yang, R.H Somani, B.X. Fu, L. Liu, B.S. Hsiao, S.H. Phillips, P. Ruth and R. Blansky (poster)

ACS Fall National Meeting, August, Chicago, IL, 2001:

1. "Strain-induced crystallization from glassy state of PET film: in-situ X-ray diffraction studies", S. Ran, Z. Wang, C. Burger, B. Chu and B.S. Hsiao (poster)

2. "Synchrotron X-ray study of ethylene-propylene copolymer under deformation", X. Fu, L. Liu and B.S. Hsiao (poster)

APS Meeting, March, Austin, TX, 2003:

1. "Shear-induced precursor structures for crystallization in isotactic polypropylene melt by rheoSAXS and -WAXD studies", B.S. Hsiao, R. Somani, L. Yang and H. Fruitwala (poster)

2. "Synchrotron Small- and Wide-Angle X-ray scattering studies of shear-induced crystallization in iPP/UHMWPE solution blends", C. Avila-Orta, R. Somani, L. Yang, B.S. Hsiao and G. Marom (poster)

ACS National Meeting, New Orleans, LA, March 23-27:

"Structural formation of amorphous poly(ethylene terephthalate) under uniaxial deformation using synchrotron radiation”, D. Kawakami, B.X. Fu, S. Ran, I. Sics, and B.S. Hsiao

\section{Yi-han Kao}

The Electrochemical Society, March, 2001: 
"Characterization of microstructures and interfaces in thin-film photovoltaic materials using synchrotron radiation: a review", Y.H. Kao

\section{Scott T. Misture}

International Symposium on Applied Ferroelectrics, Honolulu, 2000:

"The renaissance of diffraction methods: electroactive materials studies," S.T. Misture (invited talk)

DOE Workshop: Coatings on Glass: Technology Roadmap Workshop, January 2000:

"Characterization of glass surfaces, coatings, and interfaces," S.T. Misture (invited talk)

Glass and Optical Materials Division, American Ceramic Society, 2000:

"X-ray reflectivity characterization of architectural coatings on glass," M. Eber and S.T. Misture

International Congress on Glass, 2000:

"X-ray reflectivity and atomic force microscopy for characterization of architectural coatings," S.T. Misture

Accuracy in Powder Diffraction, NIST, 2001:

“Accurate High Temperature Diffraction Using a Custom Diffraction Furnace", S.T. Misture (invited talk)

Denver X-Ray Conference 2001:

1. "In Situ High Temperature Study of Silver Behenate Reduction to Silver Metal Using Synchrotron Radiation", T. Blanton, M. Lelental, S. Zdzieszynski and S.T. Misture

2. "Evaluation of specimen displacement errors in high temperature powder diffraction furnaces", S.T. Misture, C.R. Hubbard and X.L. Wang

3. "X-ray reflectivity and atomic force microscopy for characterization of coatings on glass", S.T. Misture (invited talk) 


\section{John Parise}

American Crystallographic Association Meeting in St. Paul, Minnesota, July 21-27, 2000:

"Structure of $\mathrm{Na}_{16}\left(\mathrm{Nb}_{12.8} \mathrm{Ti}_{3.2}\right) \mathrm{O}_{44.8}(\mathrm{OH})_{3.2} \cdot 8 \mathrm{H}_{2} \mathrm{O}$, a selective ion exchanger for sequestration of $\mathrm{Sr}^{2+}$, from a twinned $5 \times 8 \times 8$ micro m crystal using synchrotron X-ray radiation source," A. Tripathi, J.B. Parise, M. Nyman and T.M. Nenoff (poster)

American Crystallographic Association Meeting in Los Angeles, California, July 21-26, 2001:

"Maximizing ion exchange capacity in zeolites: structure solution of some novel compounds using synchrotron X-Ray sources," A. Tripathi and J.B. Parise (poster)

\section{Awards related to these presentations:}

Pauling Prize for best poster presentation, ACA July 21-27 St Paul, MN (2000)

[http://www.hwi.buffalo.edu/ACA/Society-Info/award-winners.html]

Peggy Etter award for best abstract and talk, ACA July 21-27 St Paul, MN (2000)

[http://www.hwi.buffalo.edu/ACA/Society-Info/award-winners.html]

$222^{\text {nd }}$ National Meeting of the American Chemical Society, Chicago, IL, August 26-30, 2001:

"Synthesis and characterization of novel microporous and condensed metal niobate and silicotitanate materials", T.M. Nenoff, M. Nyman, A. Tripathi, J.B. Parise and R.C. Ewing (oral presentation)

National Synchrotron Light Source (NSLS) Annual User Meeting, Upton, NY, 2001:

1. "In situ synchrotron X-ray powder diffraction studies: an effective method to elucidate the decomposition characteristics of ceramic precursors", S. Devi, J.B. Parise, R.J. Gambino, S. Sampath, H. Herman, Y. Lee and J.C. Hanson (poster)

2. "Following transformations in microporous materials using synchrotron X-ray powder diffraction", Y. Lee, J.B. Parise, J.C. Hanson, J.A. Hriljac and T. Vogt (poster)

ACA National Meeting, Minneapolis, July 22-27 2000: 
“Temperature and humidity-dependent cation relocation in zeolites", Y. Lee, J. Parise, G. Jones, D. Corbin and J. Hanson (poster)

“A novel niobium tantalate”, A. Tripathi, J. Parise, M. Nyman and T. Nenoff (poster)

MRS Fall Meeting (Material Research Society), Nov. 27- Dec. 1, 2000, Boston, U.S.A.:

"A new porous lithosilicate with a high ionic conductivity," S.-H. Park, H. Liu, C.P. Grey and J. B. Parise (poster)

NECZA (North East Corridor Zeolite Association conference) conference, December 8, 2000, Philadelphia, USA:

“ $\mathrm{Cs}_{14} \mathrm{Li}_{24}\left[\mathrm{Li}_{18} \mathrm{Si}_{72} \mathrm{O}_{172}\right]_{14} \mathrm{H}_{2} \mathrm{O}$ : a new nono-porous lithosilicate with a superionic conductivity and high ion-exchange capacity," S.-H. Park, J.B. Parise, H. Gies, H. Liu, C.P. Grey and B.H. Toby (chosen as the best Poster Presentation)

ESRF-ILL Workshop “Environmental Studies Using Neutron and Synchrotron Facilities”, Grenoble, France, Feb. 20-21, 2001:

"X-ray and neutron studies of the optimized synthesis, the structure and the transformations involving novel ion exchangers", J.B. Parise (invited talk)

also published on the web in ESRF Newsletter, No. 35: June 2001; http://www.esrf.fr/info/science/newsletter/jun01/ion-exch.html also published in J.B. Parise, "Old ions for new" in ILL on-line publication "Neutrons and New Materials" http://www.ill.fr/dif/ILL-New-Materials/

Seminar Series, SUNY at Stony Brook, June 1, 2001:

"Some Applications of Synchrotron X-ray and Neutron Diffraction to the crystal chemistry of microporous material," Y. Lee (talk)

$13^{\text {th }}$ International Zeolite Conference, July 8-13, 2001, Montpellier, France:

“Optimized synthesis and structural properties of lithosilicate RUB-29," S.-H. Park and J.B. Parise (talk) 
International Zeolilte Association Meeting Montpelier, France, July 13-18, 2001:

1. "Optimized synthesis and structural properties of lithosilicate”, S.H. Park, J.B. Parise and H. Gies (oral presentation)

2. "SOMS: Sandia Octahedral Molecular Sieves. A new class of ion exchangers selective for the removal of $\mathrm{Sr}^{2+}$ from waste streams", T.M. Nenoff, M. Nyman, A. Tripathi,, J.B. Parise, W.T.A. Harrison and R.S. Maxwell (oral presentation)

3. "Characterization of a new mMember of the MFI family: [Li-Si-O]-MFI", S.-H. Park, M. Kleinsorge, H. Liu, C.P. Grey and J.B. Parise (poster)

\section{Peter W. Stephens}

Böhringer Ingelheim Pharam KG, Biberach, Germany, February 12, 2001:

“Anwendungsmöglichkeiten der modernen Pulverdiffraktometrie”, R. Dinnebier

University of Nancy, France, March 19, 2001:

"Interdisciplinarity in crystallography and mineralogy at the example of modern powder diffraction", R. Dinnebier

American Physical Society, Seattle, WA, March 12-16, 2001:

"Polymeric Fullerene Chains in $\mathrm{KC}_{60}$ and $\mathrm{RbC}_{60}$ ", P.W. Stephens (invited talk)

Accuracy in Powder Diffraction III, conference at NIST, April 22-25, 2001:

"Bond length distribution of $\mathrm{RbC}_{60}$ ", A. Huq, G.M. Bendele, R.M. Ibberson and Peter Stephens, (poster)

University of Stuttgart, Germany, May 30, 2001:

"Interdisziplinarität in der kristallographie am beispiel der modernen pulverdiffraktometrie", R. Dinnebier (Habilitation lecture)

Max-Planck-Institute for Solid State Research at Stuttgart, Germany, July 13, 2001: 
"Modern powder diffraction across the sciences", R. Dinnebier

University of Erlangen, Germany, July 20, 2001:

"Möglichkeiten und grenzen moderner pulverdiffraktometrie an synchrotronstrahlquellen”, R. Dinnebier

Denver X-ray Meeting, August 2, 2001:

1. "Non-traditional powder crystallography in the petrochemical industry", J.A. Kaduk (invited talk)

2. "Elemental and mineralogical analysis of punic make-up", A. Huq, P.W. Stephens, H. Minous, N. Ayed, M. Papiz and M. Pantos (poster)

3. "Surface area determination of interstratified hyllosilicates in athabasca oil sands from synchrotron X-ray scattering domain size," O.E. Omotoso, R.J. Mikula and P.W. Stephens (poster)

University of Köln, Germany, November 7, 2001:

"Pulverdiffraktometrie in situ", R. Dinnebier

Department Seminar, Ecole Polytechnique Federal de Lausanne, Italy, Nov. 28, 2001; University of Pavia, Italy, Nov. 30, 2001 and Max Planck Institut fur Festkorperforschung, Stuttgart, Germany, Dec. 3, 2001:

"Malaria, Synchrotron radiation, and Monte Carlo", P.W. Stephens (invited talk) 